\title{
Agricultural Experiment Station Faculty and Administrator Attitudes and Perceptions Regarding Placing Research Results on the World Wide Web
}

\author{
Roger Kjelgren ${ }^{1,2}$
}

\begin{abstract}
ADDITIONAL INDEX WORDs. Internet, peer review, online publishing, open access
SuMMARY. I investigated perceptions of Agricultural Experiment Station (AES)supported faculty and administrators regarding faculty involvement in placing AES-supported research on the World Wide Web (Web). Four populations were surveyed with a Web-based survey: all AES-supported faculty at Utah State University; AES-supported faculty in distinct horticulture departments at land-grant universities; AES state directors; and department heads/chairs in AES-supported horticulture departments. The survey queried the merits of placing research results on the Web and the degree of institutional support and actual faculty involvement in this process. All four groups agreed that placing AES-supported research results online was important and that faculty will need to become more conversant with the Web to do so. Overall, department heads were the least supportive of faculty involvement with placing research findings on the Web, and faculty were ambivalent regarding whether it interfered with other work. Most respondents reported little in the way of institutional support, policies, and mechanisms to help faculty get research online. About one-third of both faculty groups were able to balance an online AESsupported research presence with existing duties, and interest in doing so was high in the rest. Developing an online research presence is an opportunity for AES-supported faculty to make more of their agricultural research findings available in new and interpretive way to a broader constituency, both traditional and new. Doing so will likely require leadership from state AES directors in terms of policies and technical support.
\end{abstract}

$\mathrm{T}$ he World Wide Web accessed over the Internet has dramatically increased information communication in the scientific community, including horticulture and all research supported by the Agricultural Experiment Station as funded by the states and U.S. Department of Agriculture (USDA). The Web has facilitated research within the scientific community by increasing the ease and speed of publishing scientific papers, increased database-searching capability, and made full-text reprints of subscription print journals easily accessible. Further, online dissemination on the Web has expanded rather than diminished the reach of print journals. While print journal usage in university libraries may be declining (De Groote and Dorsch, 2001; Vaughn, 2003), the overall number

Technical contribution No. 7758 of the Utah Agricultural Experiment Station.

${ }^{1}$ Department of Plants, Soils, and Biometeorology, Utah State University, Logan, Utah 84332-4820

${ }^{2}$ Corresponding author. E-mail: rkjel@usu.edu of print citations has increased (De Groote et al., 2005). The Web has an even larger potential to disseminate greater kinds of scientific information in more ways to a broader audience, one with a stake in science and the consequences of science.

Nearly transparent access to fulltext and abstracted scientific information on the Web increases the value of that information. However, access also creates turmoil regarding who captures that value in terms of revenue and costs, which, indirectly, may limit access. Rapid increases in availability of online reprints and e-prints of online journals (Wren, 2005) and document acquisition through interlibrary loans have led to a decline in library subscriptions (Worlock, 2001). Declining print subscriptions reduce revenue and increase unit print costs for commercial publishers and scientific societies that recoup their expenses through online subscription costs (Renner, 2002) that can limit access, particularly abroad (Adusumilli and Mullerad, 2004).
Increasing subscription costs is stimulating alternative ways of extending research to the broader scientific community. Open-access (or nominal subscription fee) peerreviewed publishing in online-only journals is surging in many disciplines (Varmus et al., 2001; Vaughan et al., 2002) as a lower-cost response to rising subscription costs (Gass, 2005). However, open-access journals are perceived as a threat in principle by many commercial publishing houses (Banks, 2004), particularly in the life sciences (see Biomed Central, 2005; Public Library of Science, $2005)$. Although supported in principle, open-access publishing may pose a fiscal threat in practice to scientific societies that rely on revenue from the page-charge model (Frank, 2001). However, online-only openaccess journals allow scientists in less affluent countries, who otherwise may be limited by costs, to participate in the worldwide scientific community (Adusumilli and Mullerad, 2004).

A subtle but key change ushered in by the Web is the ability to provide a context and decentralized access/ online archiving for scientific articles. In other disciplines, online publishing of non-peer-reviewed scientific (or "gray literature")—such as pilot studies, nonsignificant results, databases, appendices - on institutional Web sites is recognized for potentially providing contextual understanding (Banks, 2004). Also, publishing reprints/online archiving of both online and print journal articles on institutional Web sites allows immediate, decentralized access (Wren, 2005 ) that can have a significant citation impact (Swan and Brown, 2004) and offers the benefit of being assessed in the context of a researcher's larger body of work.

Agricultural and horticultural research supported by the AES has historically been disseminated to two stakeholder communities. The AESsupported scientific community shares within itself the immediate results via commercial and scientific society print journals, while the general public or industry groups receive the repackaged and targeted results via Cooperative Extension. Summaries of AESsupported research (AES-SR) are available online via the Current Research Information System (CRIS; USDA, 2005), but peer-reviewed, 
full-text reprints online are generally limited to those at institutions with subscriptions to scientific society publisher journals. Also, the body of horticultural knowledge not readily available on the Web includes smaller commodity journals without full-text or abstract availability online as well as unpublished or appendix results, both of which can be of interest to the scientific community.

Finally, the Web creates the potential opportunity for an interpretive narrative structure for research publications that AES-supported researchers place on their institutional Web sites. Such a narrative can benefit not only colleagues but also the interested general public that historically has been profoundly unaware of the AES (Rhodus and Hoskins, 1996). However, time and energy must be invested to gather, organize, and structure AES-SR for the Web. AESsupported faculty will probably need to be involved in this information processing to some degree because they are telling their own story, but many are already overburdened with demands on their time. This survey was conducted to determine attitudes and perceptions of AES-supported faculty and AES-related administrators regarding using the Web to extend the kind, reach, and interpretation of AES-SR findings, and the extent of faculty involvement in the process.

\section{Methods}

This study was conducted under the auspices of the Experiment Station Committee on Organization and Policy leadership training program and the Utah Agricultural Experiment Station (UAES). I selected two general populations for this study with two subpopulations each:

- Administrators from original (Morrill Act 1862) land-grant institutions-specifically, heads or chairs of horticulture departments or, if they did not have a horticultural department, a plant science department, and AES directors (48 each contacted);

-AES-supported faculty-all AES-supported faculty at Utah State University (USU) as a cross-section of all supported disciplines at one representative institution (93 contacted); all faculty from 21 exclusively horticulture departments as a represen- tative subset of AES-supported disciplines (450 contacted).

The survey consisted of statements that asked each respondent the degree to which they agreed with, or weighted the importance of, the statement, as well several direct questions with a yes/no response. The first two survey items queried perceptions of the potential benefits of the Web to AES-SR:

1. "Placing AES-supported research findings on the Internet benefits the AES, affiliated departments, and faculty with AES appointments."

2. "The benefits from placing AESsupported research findings on the Internet include the following (please rank as to importance): (a) to provide interpretation of research to the interested general public and industry groups; (b) to create a presence and awareness of your institutional unit in the larger online world; (c) as a collegial reprint service of peer-reviewed publications for colleagues; (d) to recruit graduate students; (e) to communicate research accomplishments to administrator; $(f)$ to stay competitive with other institutional or academic units."

Survey items 3-7 queried attitudes regarding placing more kinds of AES-SR findings online, and expanding to a larger audience through online-only journals, in essence broadening information and audience. These items were part of a follow-up survey of the same number of administrators and faculty members in each group conducted in late Jan. 2006.

3. "Posting AES-supported research from peer-reviewed niche or commodity journals, preliminary findings, and trial results on the Web through your institution for scientists, stakeholders, and the interested public that would otherwise be unavailable online is consistent with the mission of the Agricultural Experiment Station in your state."

4. "Publishing AES-supported research in peer-reviewed, online-only journals, either open access or nominal subscription, that would be more widely available to scientists, stakeholders, and the interested public is consistent with the mission of the Agricultural Experiment Station in your state."

5. "The AES at your institution should encourage the posting of AESsupported research findings from peerreviewed niche or commodity journals, preliminary findings, and trial results on the Web."

6."Publishing AES-supported research findings in peer-reviewed online-only journals, either open access or nominal subscription, can potentially have scientific credibility and impact equal to traditional peerreview print journals."

7. "Have you published a scientific paper in an online journal in the past three years? If so, could you record the number?"

Survey items 8 and 9 queried administrators and faculty members on the ability of faculty members to place research findings online, and an indirect perception of potential obstacles.

8. "Achieving the benefits of placing AES-supported research findings on the Web will require that faculty become conversant to some degree with organizing, formatting, and structuring their research results for the Web, then posting to the Web."

9. "The significant time investment required to prepare and place research findings on the Web can potentially interfere with faculty research responsibilities."

Survey items 10-12 queried as to support structures; questions 11 and 12 were not asked of USU faculty because the answers were already affirmative to both questions:

10. "My academic unit has a qualified technical support person to work directly with faculty to obtain, organize, format, structure, and post research findings on the Web."

11. "Does your institutional unit have a specific policy for assisting AESsupported faculty in publishing research results on the Web?"

12. "Does your institutional unit have a specific software-based mechanism for allowing AES-supported faculty to publish research findings on the Web?”

The survey for administrators ended at this point. UAES-supported faculty members were asked several specific questions about the UAES online-reporting mechanism MYAG (USU, 2006), if they used it, what they used it for, and if it had merit (survey item 13). USU and horticultural faculty were then asked the following questions:

14. "Do you post your research findings on the Web, either by yourself or by directing a Web programmer?" 
- If no, then the survey branched to a question asking if they would like to learn how to place their research findings on the Web;

- If the answer was yes, they were then asked to select from several levels of interaction with placing research findings on the Web: doing it all themselves; interacting with a Web programmer; publish reprints; publish other, nonpeer-reviewed publications; provide interpretation of research results.

The survey ended for the two faculty groups where they were asked to agree or disagree with the following statements:

15. "I am able to get my research findings on the Web, but this effort comes at the cost of my other research efforts."

16. "The Experiment Station could do more to assist faculty with UAES appointments in placing their research findings on the Web."

The survey was submitted to the USU Institutional Review Board as being completely anonymous and was approved on 15 Feb. 2005. It was administered online through a subscription survey service (Keysurvey, 2006). The administrator survey was pretested on the head of the Department of Plants, Soils, and Biometeorology at USU, and the faculty survey was pretested on four departmental colleagues. Data were analyzed through histograms and descriptive statistics. In the following text, strongly agree, agree, neutral, disagree, and strongly disagree were abbreviated as $\mathrm{SA}, \mathrm{A}, \mathrm{N}, \mathrm{D}$, and $\mathrm{SD}$, respectively.

\section{Results and discussion}

Response rates. The overall response rate varied widely among the four groups. The USU AESsupported faculty had the highest response rate, $48 \%$ of the 92 faculty contacted. Of these, $30 \%$ were assis$\operatorname{tant}, 36 \%$ associate, and the remainder full professor. The horticulture faculty had the lowest survey response rate, $11 \%$ of 450 , of which was heavily weighted toward full professor, $65 \%$, and the remaining $35 \%$ evenly split between assistant and associate. The AES directors had the lowest administrator response rate, $25 \%$, while $33 \%$ of department heads responded. Response rates to the follow-up survey (items 3-7) were lower overall at $21 \%, 27 \%$, and $37 \%$ for AES admin- istrators, department heads, and USU faculty, respectively, but increased slightly to $12 \%$ for horticultural faculty. The low overall response rate among administrators and horticultural faculty would imply that this topic was not of sufficient importance to warrant completing the survey.

Potential Benefits. All four groups saw benefits in placing AESsupported research findings on the Web (survey item l; data not shown). AES directors, more attuned to stakeholders and the larger political impact of AES-supported research, saw benefits, as $33 \%$ and $42 \%$ agreed or strongly agreed (A/SA), respectively. Consistent with this, many commented on the importance of getting research results into stakeholder hands. Department heads, on the other hand, are probably less attuned, as their agreement was weaker $(44 \%$ and $6 \% \mathrm{~A} / \mathrm{SA}$ ), and interestingly but consistently, none commented, suggesting that they considered it a lower priority. Both faculty groups also saw benefits, although horticulture faculty were a bit more ambivalent, $36 \% / 28 \%$ A/SA, vs. $52 \% / 27 \%$ A/SA for the USU faculty. Many faculty comments emphasized the importance of maintaining peer review, and one noted that online-only journals are not counted as "refereed" at their institution.

Of six possible benefits of placing AES-SR on the Web (survey item 2), the more intangible, outward-looking ones were ranked the most important, while the more bureaucratic reasons were much less important (Fig. 1). Almost $75 \%$ of all responses agreed/strongly agreed that having an online presence was important (Fig. 1A). Two other possible outward-looking benefits, using the Web to provide interpretation (Fig. 1B) and as an online archive to provide reprints (Fig. 1C), also elicited agreement $(68 \%$ and $64 \% \mathrm{~A} / \mathrm{SA}$ across all groups, respectively). Two more inward-looking possible benefits of placing AES-SR online, recruiting graduate students (Fig. ID) and staying competitive (Fig. 1E), garnered less agreement $(56 \%$ and $55 \% \mathrm{~A} / \mathrm{SA}$, respectively). Perhaps the most mundane and bureaucratic potential benefit, online reporting to administrators (Fig. IF), had only $32 \% \mathrm{~A} / \mathrm{SA}$ across administrators and horticul- ture faculty. However, the higher agreement of the USU faculty $(71 \%$ A/SA) was likely because they are expected to submit yearly accomplishments to administrators through an existing UAES online reporting mechanism.

Several trends were apparent. Department heads were more ambivalent about possible benefits of placing AES-SR online as compared with AES directors, particularly in terms of providing interpretation, reprints, and graduate student recruitment. By contrast, several AES director comments emphasized the benefit of using the Web to provide outcomes and reports to both stakeholders and state and federal sources that fund AES research. Similarly, stronger horticulture faculty agreement with the benefit of providing interpretation online may reflect more split Extension appoints as compared with USU faculty that cross a range of disciplines with fewer extension appointments (76\% vs. $56 \%$ A/SA, respectively; Fig. 1B).

BROADENING INFORMATION AND AUDIENCE. Using the Web to make more kinds of AES-SR results available online to a wider scientific audience was strongly supported in theory but less so in application (Fig. 2). A large majority across the four groups was in agreement that putting nonpeer-reviewed AES-SR online (51\%/ $35 \%$ A/SA; survey item 3, Fig. 2A) and publishing in online-only journals $(49 \% / 32 \% \mathrm{~A} / \mathrm{SA}$; survey item 4 , Fig. 2B) were activities consistent with the AES mission. A smaller majority across all groups felt that faculty should actually be encouraged to place non-peer-reviewed research material online $(42 \% / 30 \%$ A/SA; survey item 5, Fig. 2C). Even fewer felt $(42 \% / 23 \%$ A $/ S A$; survey item 6 , Fig. 2D) that online-only journals have scientific merit equal to print journals and were opposed by a relatively substantial proportion (18\% D/ $\mathrm{SD})$. In essence, survey item 6 indirectly asked whether faculty should be encouraged to publish in online-only journals, and AES directors agreed much more strongly $(80 \%$ A/SA) than department heads (54\% A/SA; $23 \% \mathrm{D} / \mathrm{SD})$, consistent with the ambivalent responses of department heads regarding potential benefits (see Fig. 2B-D). More horticulture faculty thought that online-only 


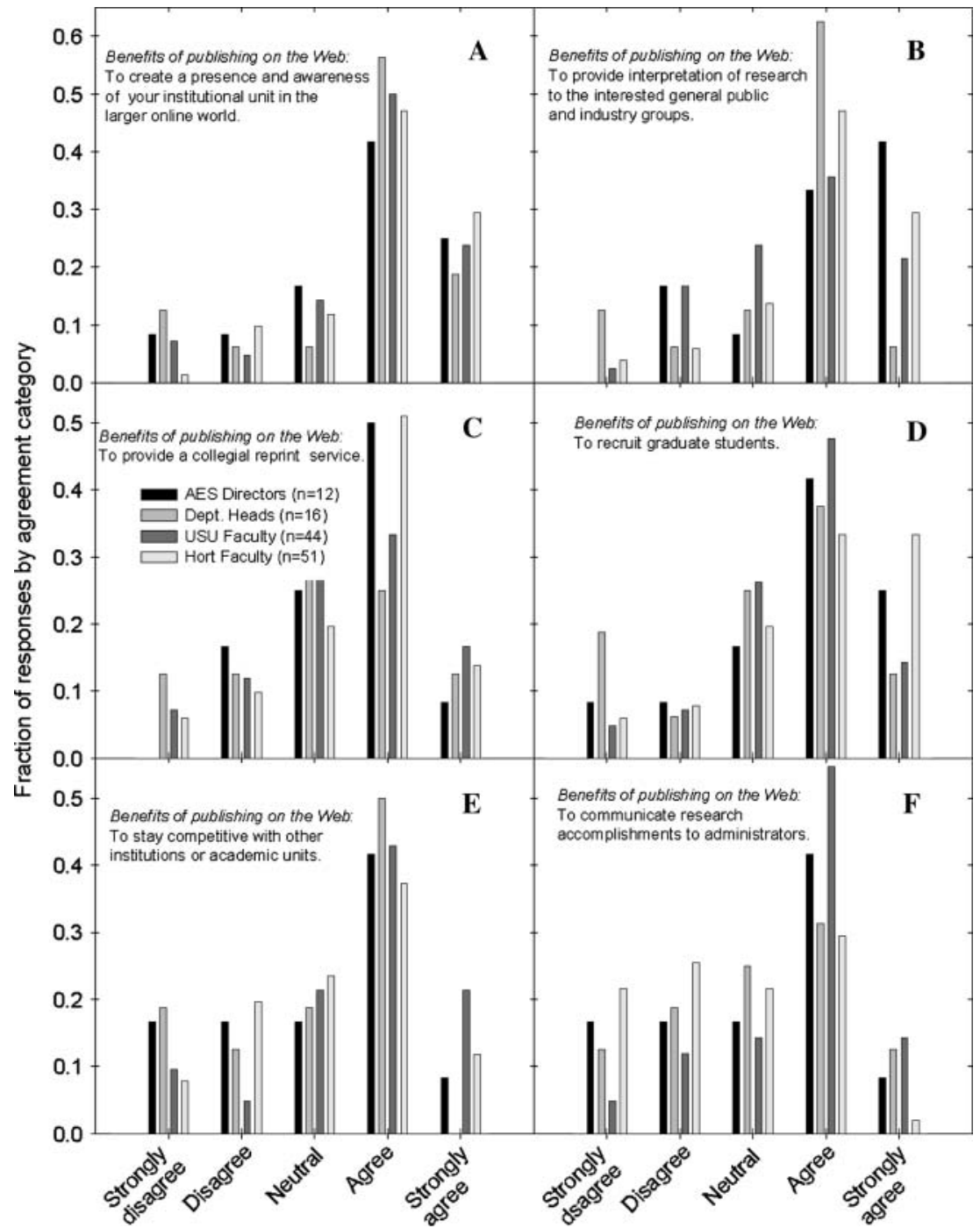

Fig. 1. Fractional response frequency rating (strongly disagree, disagree, neutral, agree, strongly agree) by AES administrators (AES directors and plant science department heads) and AES-supported faculty (all AES-supported faculty at USU and horticulture faculty of selected horticultural departments) of the importance of six potential benefits arising from placing AES-supported research findings on the Web.

journals were scientifically credible (73\% A/SA) than USU faculty $(56 \%$ A/SA, $44 \% \mathrm{~N} / \mathrm{D})$, again possibly influenced by a greater number of Extension appointments. Both faculty groups were involved in onlineonly publishing, as $19 \%$ of the USU and $29 \%$ of the horticulture faculty responded that they publish in openaccess journals (survey item 7 , data not shown).

Perceptions of obstacles. In another aspect of the importance of creating an online presence, majorities of about two-thirds in all groups were in agreement that AESsupported faculty needed to become conversant to some degree with the process of placing research findings on the Web (survey item 8; Fig. 3A). This agreement suggested a perception that working with the Web is the next step in technological skills that faculty will need to do their jobs. However, comments suggested that additional support was needed, as a third of the AES directors commented that faculty needed technical support rather than doing it themselves. Both faculty groups commented that the process needed to be relatively straight forward, and faculty and support staff needed to receive credit for the online end product, an idea previously suggested by Rhodus and Hoskings (1996).
There was less agreement regarding how much the effort might interfere with regular faculty research responsibilities (survey item 9; Fig. 3B). AES directors had a bimodal response $(51 \% \mathrm{D} / \mathrm{SD}$ vs. $41 \% \mathrm{~A} / \mathrm{SA})$, while department heads were in more agreement $(75 \% \mathrm{~A} / \mathrm{SA})$ that placing research onto the Web would interfere with research responsibilities, consistent with their ambivalent responses to the benefits of placing research results on the Web (see Fig. 1). In contrast, both faculty groups were nearly identically ambivalent $(\approx 33 \%$ A/SA, N, D/SD) about potential interference. Faculty comments on this question coalesced into a sentiment of it being easy once you have mastered the process or have technical support and difficult without adequate skills or technical support.

SupPort AND POLICIES. Both horticulture and USU faculty and department heads, disagreed $(64 \%$, $62 \%, 60 \% \mathrm{D} / \mathrm{SD}$, respectively) that their institutions had technical support to help faculty in placing research results on the Web (survey item 10; Fig. 3C). AES administrators had split perceptions with, again, a bimodal response $(42 \% \mathrm{D} / \mathrm{SD}$ vs. $50 \% \mathrm{~A} / \mathrm{SA})$, about the availability of technical support for Web page development for faculty. Comments from both faculty groups and the AES directors emphasized the absence of technical support, and several faculty comments observed that there was support at the college but not at the departmental level. These comments combined with earlier comments on survey item 9 (Fig. 3C) would suggest a support-staff/technical communicator niche that combines technical training with interpretive skills (Clark and Anderson, 2005; Pringle and Williams, 2005). Such a position could facilitate a more transparent connection between faculty, their AES-SR, and the Web and perhaps entice more of the horticulture faculty who did not respond to the survey to become engaged in online publishing.

Querying further showed that few institutions had AES-supported policies and software mechanisms for getting faculty research online (survey items 11 and 12; data not shown). Very few $(6 \%$ horticulture faculty, $11 \%$ AES directors, and no horticulture 


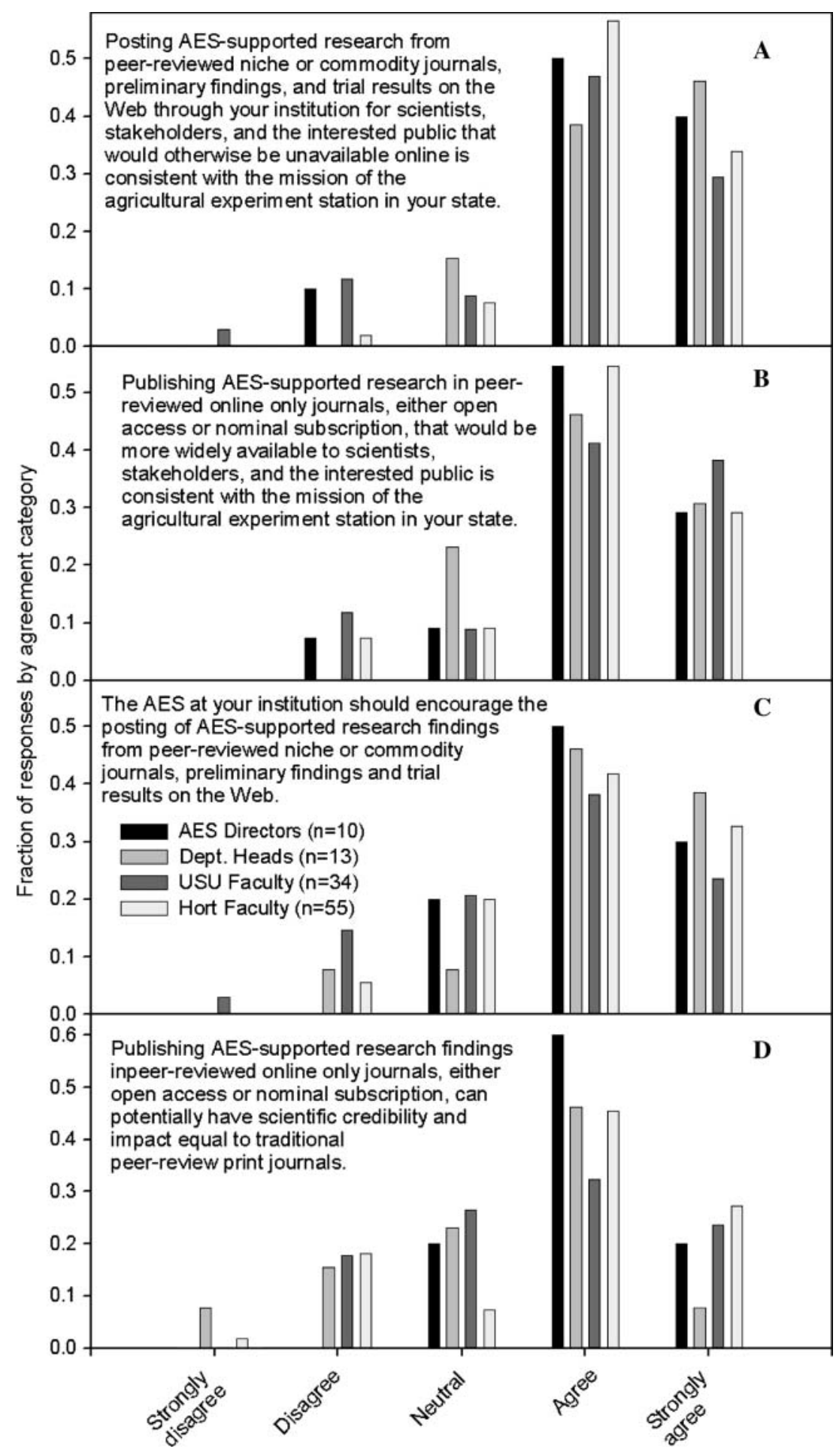

Fig. 2. Fractional response frequency rating (strongly disagree, disagree, neutral, agree, strongly agree) by AES administrators (AES directors and plant science department heads) and AES-supported faculty (all AES-supported faculty at USU and horticulture faculty at selected horticultural departments) of four statements regarding alternative approaches to publishing of AES-supported research on the Web being consistent with the mission of the AES, and the extent to which faculty should be encouraged to engage in these alternative approaches.

department heads) said that they had an AES policy to encourage faculty to publish on the Web (survey item 11). However, slightly more respondents ment heads; survey item 12). Interestingly, 25\% horticulture faculty did not know if they had a mechanism.

USU FACULTY. Utah State University UAES does have a policy and mechanism for faculty posting peerreviewed and non-peer-reviewed research and on the Web (survey item 13; data not shown). MYAG (USU, 2006) is an interactive Web site that allows UAES-supported faculty to upload citations, abstracts, and other documents, and yearly UAES faculty evaluations are based on results reported on the site. Most of the responding USU faculty (77\%) said that they use MYAG, and of those, a modest majority ( $53 \% \mathrm{~A} / \mathrm{SA})$ felt that MYAG had merit, many were neutral $(29 \%)$ and only $18 \%$ disagreed or strongly disagreed. Of the $77 \%$ of the faculty that use MYAG, only $38 \%$ said that they updated their information frequently. MYAG was used primarily for publishing citations (97\%), and a third also posted both abstracts and non-peer-reviewed AES-SR, but only $10 \%$ post full-text articles, suggesting that USU faculty view MYAG primarily as a reporting mechanism, consistent with previous importance they placed on administrative reporting.

FACULTY PARTICIPATION. Approximately $40 \%$ of both horticulture $(41 \%)$ and USU faculty $(39 \%)$ placed their research findings on the Web, either by themselves or with the support of a Web programmer (survey item 14; data not shown). Of the faculty that do publish on the Web, $41 \%$ ( $16 \%$ of total) of these among the USU faculty prepare and post research results on the Web themselves, while $52 \%$ ( $22 \%$ of total) of the horticulture faculty do it all themselves. The remainder of each group works with a Web programmer to publish results. Only 38\% of the USU faculty that post research results online use the Web to post reprints, vs. $57 \%$ of the horticulture faculty. Similar majorities $(58 \%)$ published other, non-peer-reviewed, research findings or gray literature on the Web, but similar minorities $(43 \%)$ provided some degree of interpretation of their research results online.

Both horticulture and USU faculty were ambivalent about the time cost involved in placing AES-RS online (survey item 15; Fig. 4A), 


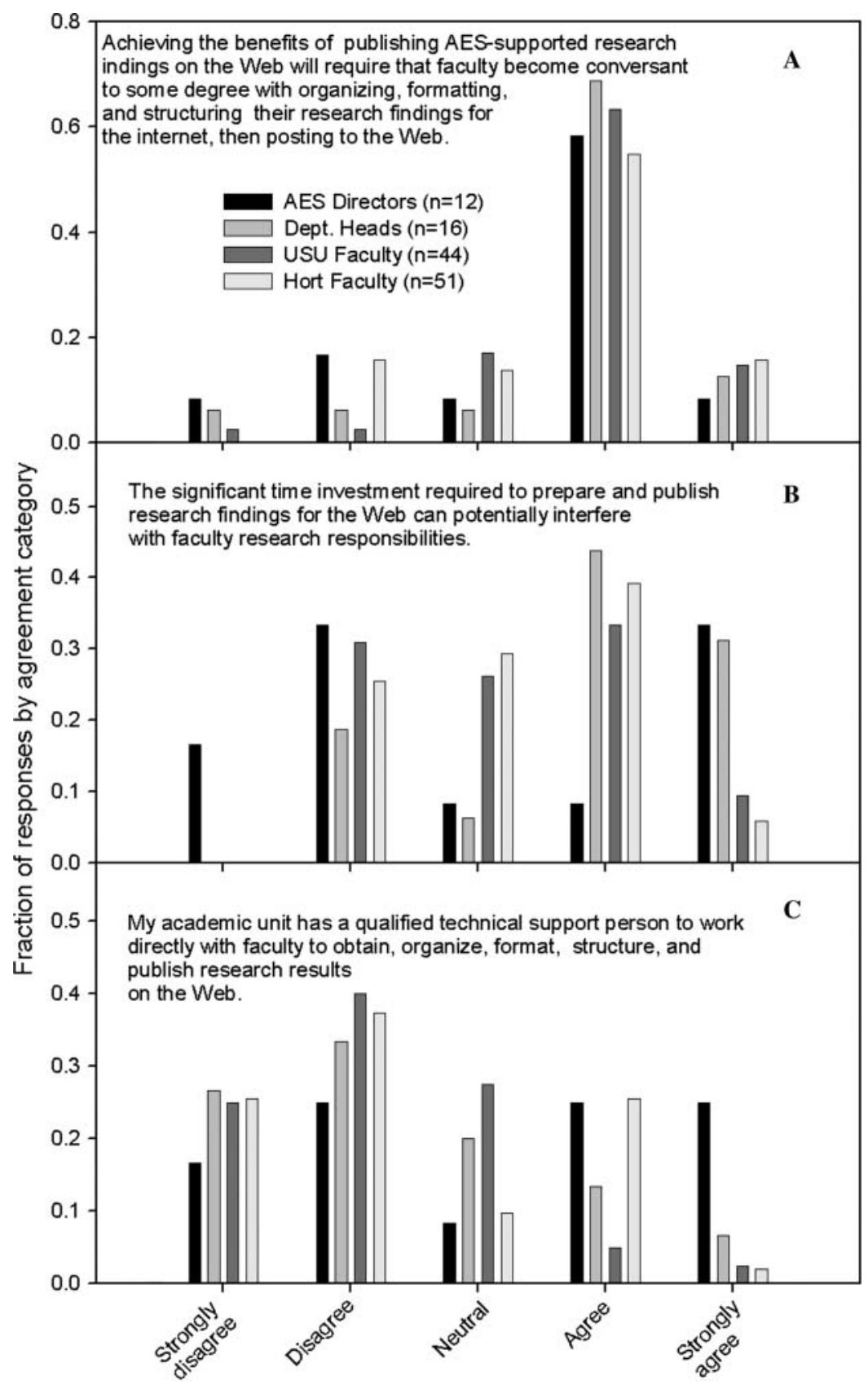

Fig. 3. Fractional response frequency rating (strongly disagree, disagree, neutral, agree, strongly agree) by AES administrators (AES directors and plant science department heads) and AES-supported faculty (all AES-supported faculty at USU and horticulture faculty) of the need and ability of faculty to be engaged in placing research findings on the Web.

echoing their previous sentiment about potential interference (survey item 9; Fig. 3C). Again, there was about a one-third split in agreement $(\mathrm{A} / \mathrm{SA}, \mathrm{N}, \mathrm{D} / \mathrm{SD})$ among both groups. The previous ambivalent perception (Fig. 3C) and this actual assessment (Fig. 4A) suggest that those engaged in placing research online are largely "making it work" in terms of balancing other responsi- bilities, but the rest may need additional resources of time or technical support to balance participation in disseminating their AES-SR online with their existing duties.

Both faculty groups were interested in becoming more engaged in publishing research results on the Web. Of those that did not publish on the Web (survey item 14, "no" response), $60 \%$ of the horticulture faculty and $75 \%$ USU faculty would like to learn. The perception among both faculty groups was that more support would facilitate greater faculty involvement in getting AES-SR results online (survey item 16; Fig. 4B). Majorities of both USU $(68 \% \mathrm{~A} / \mathrm{SA}$ vs. $2 \% \mathrm{D} / \mathrm{SD})$ and horticulture $(64 \%$ A/SA vs. $10 \%, \mathrm{D} / \mathrm{SD}$ ) faculty felt that their AES could do more to support faculty efforts at getting research results on the Web.

\section{Conclusions}

The Web offers significant opportunities for the AES to achieve its mission and serve its stakeholders. Both administrator and faculty groups see the opportunities of the Web by making a wider range of agricultural research findings available for use and interpretation to a broader constituency, both traditional and new. About one-third of the faculty members in both groups successfully balance an online presence that included a wide array of research findings and interpretations with other duties. Few are doing it without technical help, a difficult approach for other faculty who are interested in developing an online research presence but concerned about additional demands on their time. Open-access journals offer a way to publish peer-reviewed AESSR that can reach a wider audience without additional effort.

Leadership is needed to assist those AES faculty members interested in developing an online research presence beyond subscriptionaccessed reprints. Policies to encourage faculty-member skill development in structuring information for the Web can complement their existing skills, much in the same way that word processing and spreadsheet abilities have become integral skills. Equally important, technical support in the form of a technical communicator who can help faculty structure a narrative online presence, as well as technically setting up a Web site, would be a key link in making the process successful and transparent. A technical communicator could play a symbiotic role similar to statistical consultants, where faculty develop research content and objectives that are rigorously packaged with outside professional help. These data would 


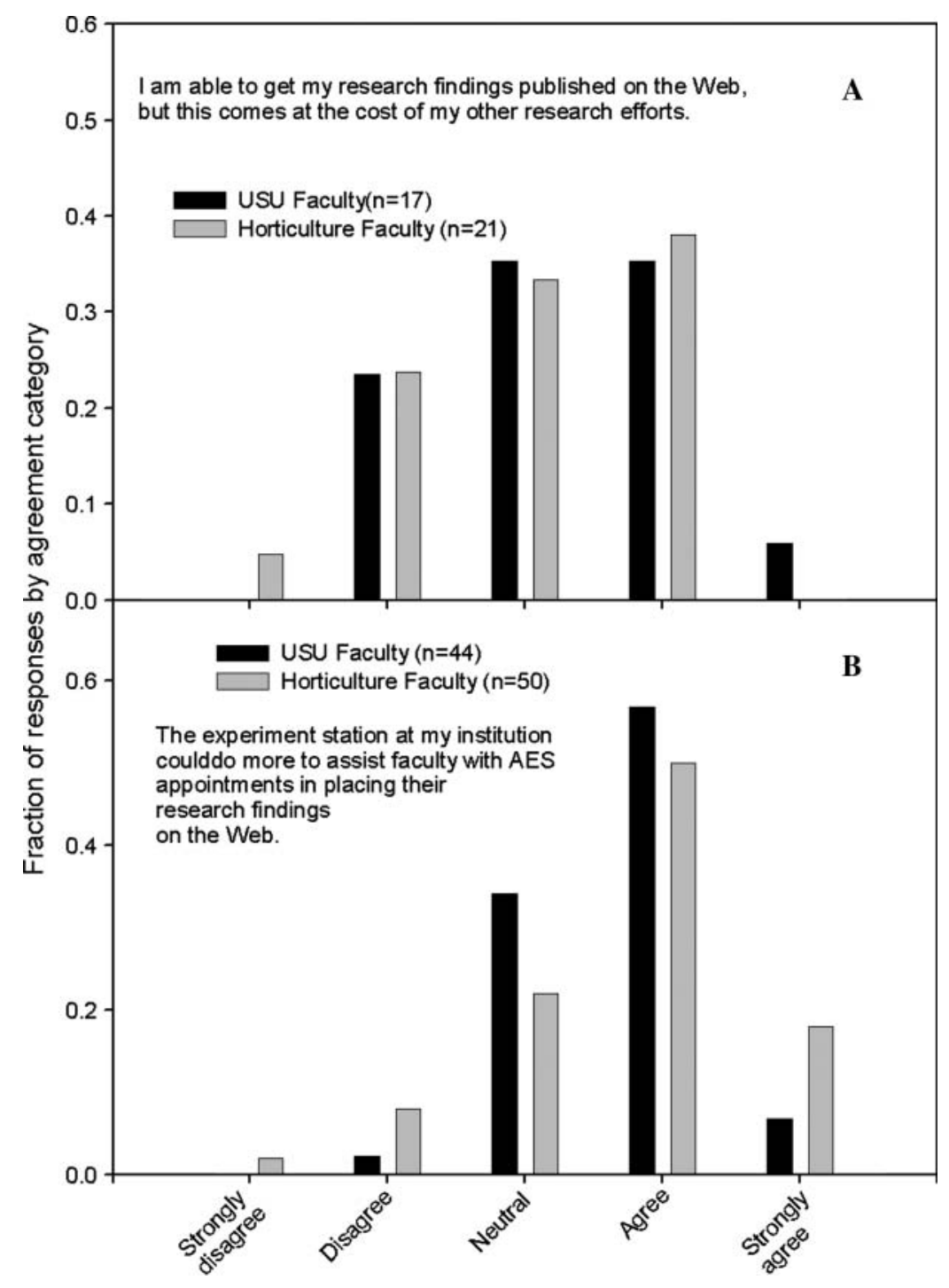

Fig. 4. Fractional response frequency rating (strongly disagree, disagree, neutral, agree, strongly agree) by AES-supported faculty (all AES-supported faculty at USU and horticulture faculty), who already publish research results on the Web, of potential costs involved in the effort, and all surveyed faculty rating of how much their experiment station could help their involvement with online publishing.

suggest that AES directors are better prepared and motivated than are department heads to provide the leadership to faculty interested in creating a greater online research presence.

\section{Literature cited}

Adusumilli, P.S. and M. Mullerad. 2004. Open access publishing: A digital bridge for developing nations? Natl. Med. J. India 17:167-168.

Banks, M. 2004. Connections between open access publishing and access to gray literature. J. Med. Libr. Assn. 92:164166.
Biomed Central. 2005. What is BioMed Central? 10 Oct. 2005. <http:// www.biomedcentral.com/info/about/ whatis>.

Clark, D. and R. Andersen. 2005. Renegotiating with technology: Training towards more sustainable technical communication. Tech. Commun. 52:289-301.

De Groote, S.L., M. Shultz, and M. Doranski. 2005. Online journals' impact on the citation patterns of medical faculty. J. Med. Libr. Assn. 93:223-228.

De Groote, S.L. and J.L. Dorsch. 2001. Online journals: Impact on print journal usage. Bul. Med. Library Assn. 89:272-278.

Frank, M. 2001. No free lunch. Nature debates-Aug. 20. 6 Oct. 2005. <www. nature.com/nature/debates/e-access / articles/frank.html>.

Gass, A. 2005. Paying to free science: Costs of publication as costs of research. Serials Rev. 31:103-106.

Keysurvey. 2006. Create surveys online. 15 Jan. 2006. <www.keysurvey.com>.

Pringle, K. and S. Williams. 2005. The future is past: Has technical communication arrived as a profession? Tech. Commun. 52:361-370.

Public Library of Science. 2005. PLoS core principles. 10 Oct. 2005. <http:// www.plos.org/about/principles.html>.

Renner, R. 2002. Online pioneer winds up lost in cyberspace. Science 297:14681469.

Rhodus, T. and J. Hoskins. 1996. The Internet: Changing the way horticulturists communicate. HortTechnology $4: 308-314$.

Swan, A. and S. Brown. 2004. Authors and open access publishing. Learned Publishing 17:219-224.

U.S. Department of Agriculture. 2005. Current Research Information System (CRIS). 19 Oct. 2005. <http://cwf. uvm.edu/cris/ $>$.

Utah State University. 2006. MYAG. 24 Oct. 2006. <https://myag.usu.edu/login/ index.php?ret_link=\%2F\&type $=$ notLogged $>$.

Varmus, H.E., M. Ashburner, P.O. Brown, M.B. Eisen, C. Khosla, M. Kirschner, R. Nusse, and M. Scott. 2001. Building a 'GenBank' of the published literature. Science 291:55125513.

Vaughn, K.T. 2003. Changing use patterns of print journals in the digital age: Impacts of electronic equivalents on print chemistry journal use. J. Amer. Soc. Info. Sci. Technol. 54:1149-1152.

Vaughan, K.T., J. Blixrud, K.L. Hahn, and D. Cohn. 2002. The changing face of scientific communication: Developing new models for scholarly publishing in the electronic environment. Proc. Amer. Soc. Info. Sci. Techol. Annu. Mtg. 39:480-481

Worlock, D.R. 2001. The best of times, the worst of times-Nature debatesOct. 18. 6 Oct. 2005. <http://www. nature.com/nature/debates/e-access / Articles/worlock.html>.

Wren, J.D. 2005. Open access and openly accessible: A study of scientific publications shared via the Internet. BMJ 330:1128-1131. 